Institute of

Technical Thermodynamics

Surface Analytical Methods for the

Development of Electrochemical Components of

Polymer Electrolyte Fuel Cells

I. Biswas, P. Gazdzicki, M. Schulze

Deutsches Zentrum für Luft- und Raumfahrt, Pfaffenwaldring 38-40,

70569 Stuttgart, Germany

\section{FT-Infrared Absorption}

\section{Spectroscopy}

Environmentally friendly energy converters with high gravimetric energy density

\section{$\rightarrow$ Fuel cell cars}

Combination with water electrolysers

$\rightarrow$ Decentral hydrogen power plants

$\rightarrow$ Balancing of electric grid

$\rightarrow$ Storage of excess energy from renewable sources

$\rightarrow$ Distributed hydrogen generation for fuel cell cars

Emission free auxiliary power units

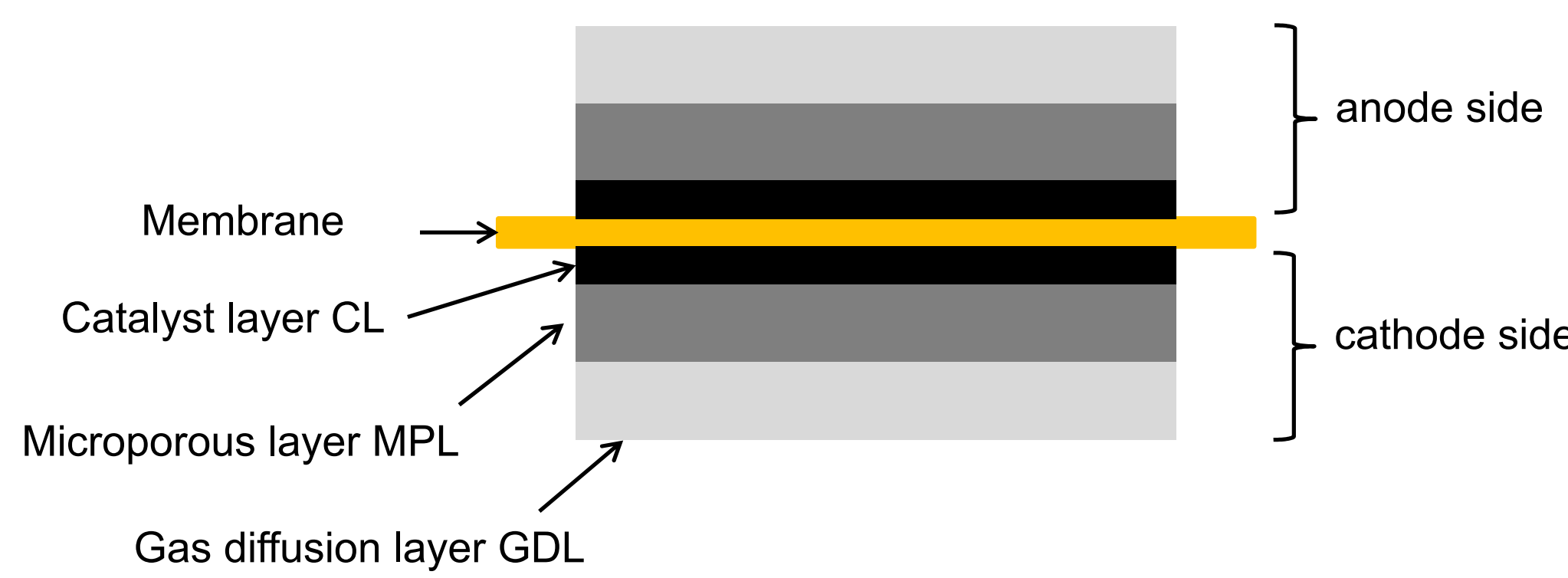

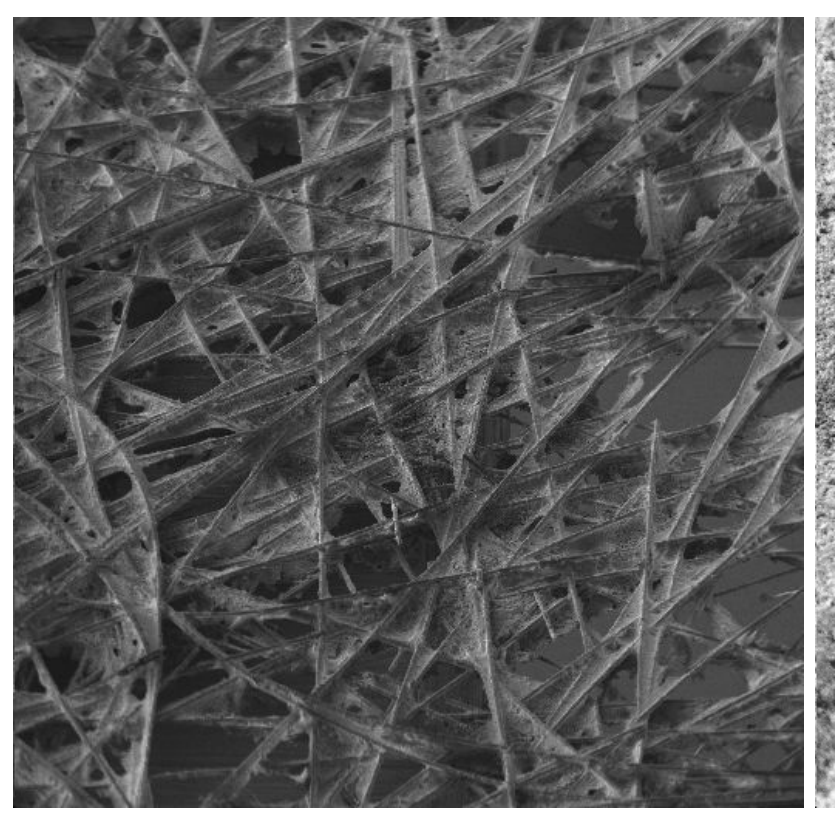

GDL

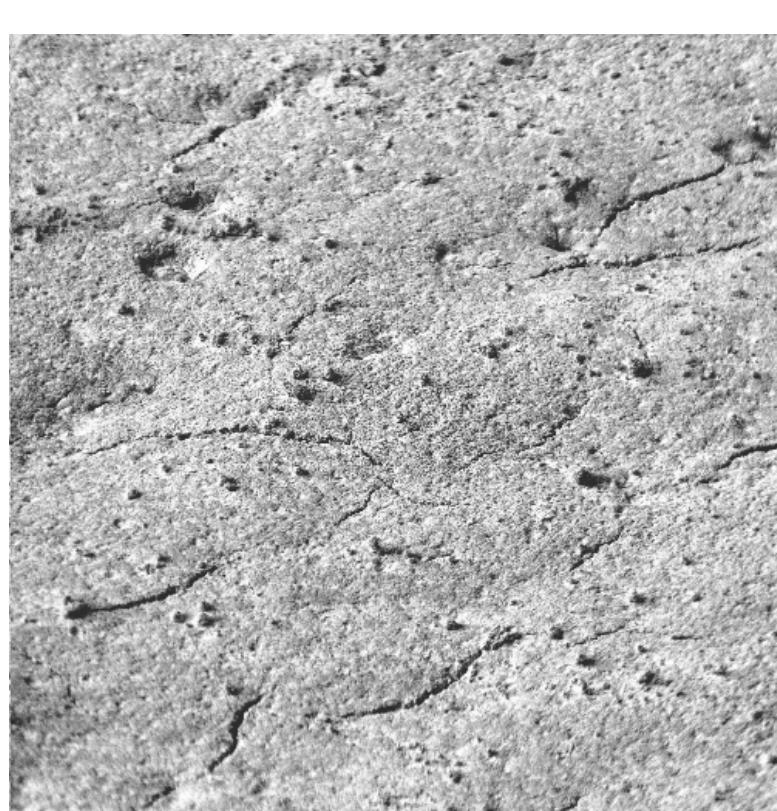

MPL

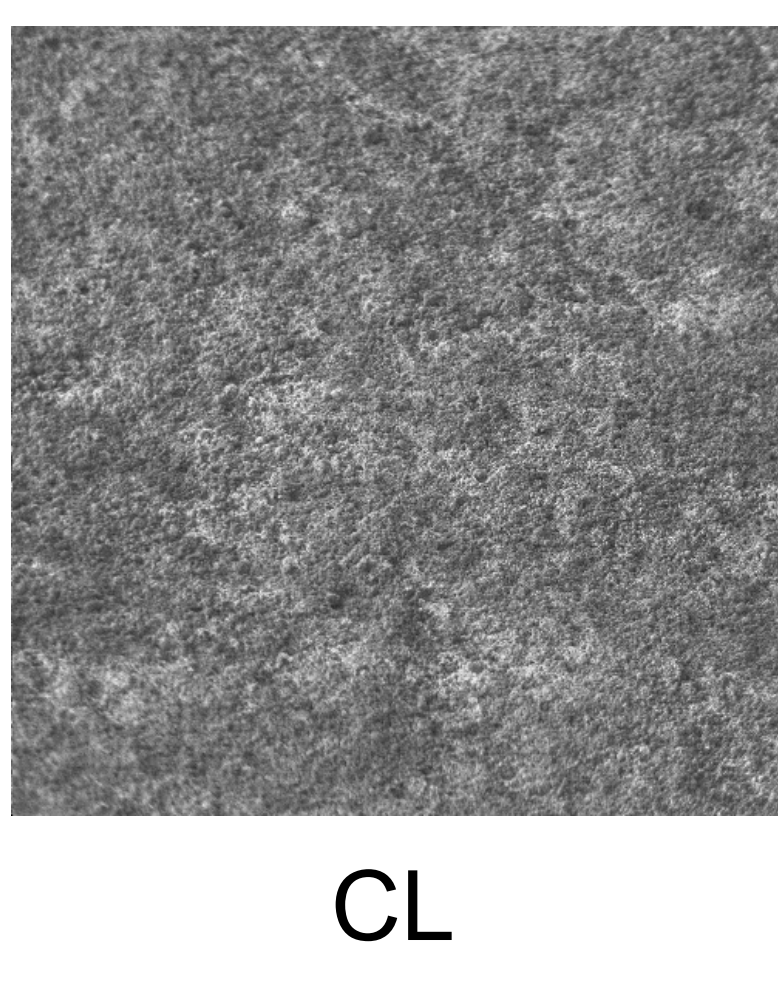

( $3 \times 3 \mathrm{~mm}$ SEM images)

\section{Requirements to Fuel Cells}

Long term stability

Cost efficiency: reduction of $\mathrm{Pt}$

Highly dynamic load flexibility for fuel cell cars and hydrogen power plants

\section{Known Problems}

- Water management:

humid membranes $\leftrightarrow$ dry GDLs

electrolyte conductivity $\leftrightarrow$ gas transport

- Catalyst degradation:

migration, poisoning, agglomeration

- GDL degradation:

change of hydrophobicity

\section{Requirements to Surface Analytics}

- Characterisation of hydrophobicity

- Investigation of outer and inner surfaces of pore networks

- Lateral chemical mapping

- Elemental detection of trace amounts of catalysts

- Elemental distribution of catalysts in layers and in grains
Molecular vibrations related to dipole moment changes

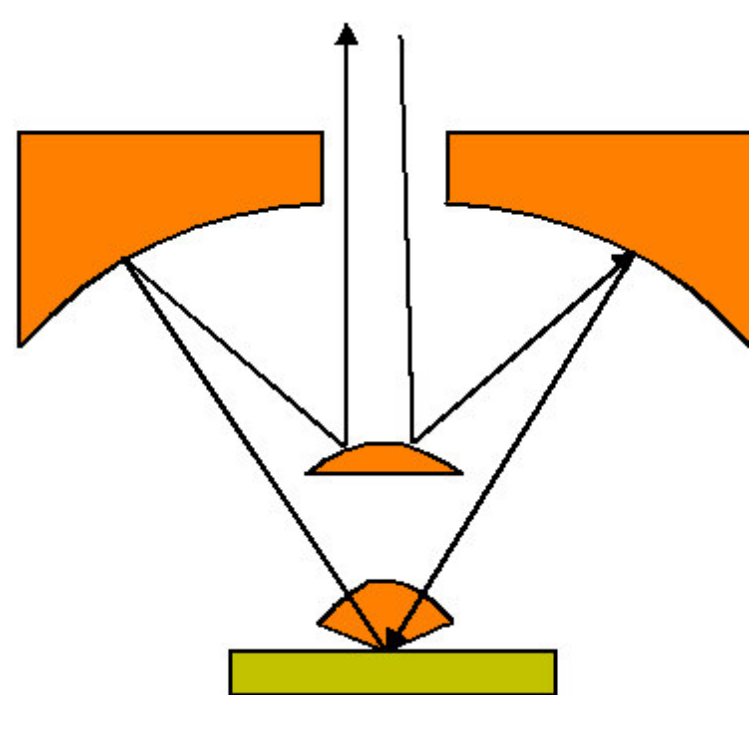

Attenuated total reflection (ATR):

$\sim 5 \mu \mathrm{m}$ surface information, sample contact

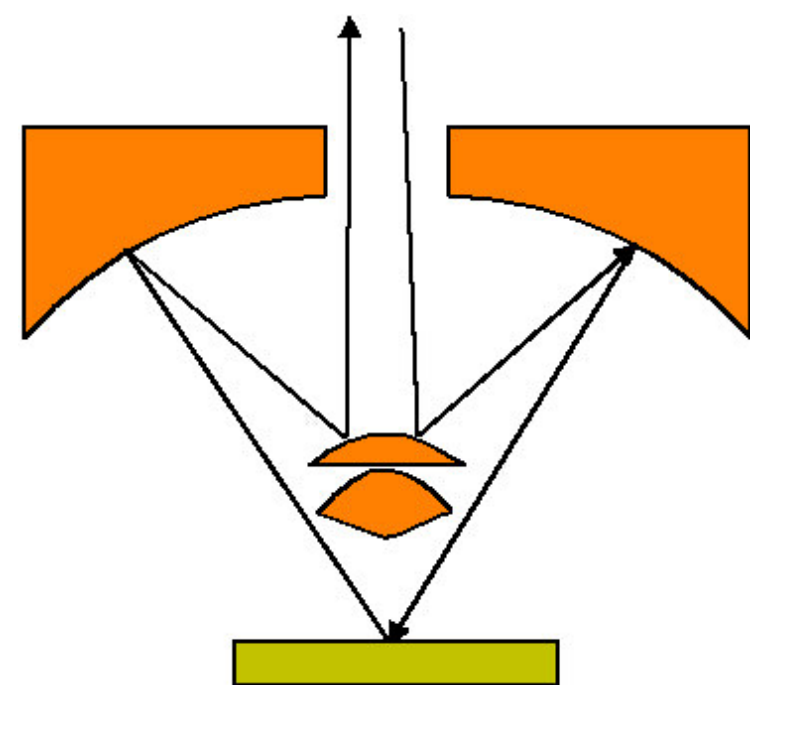

Reflection: weak signal on dark samples

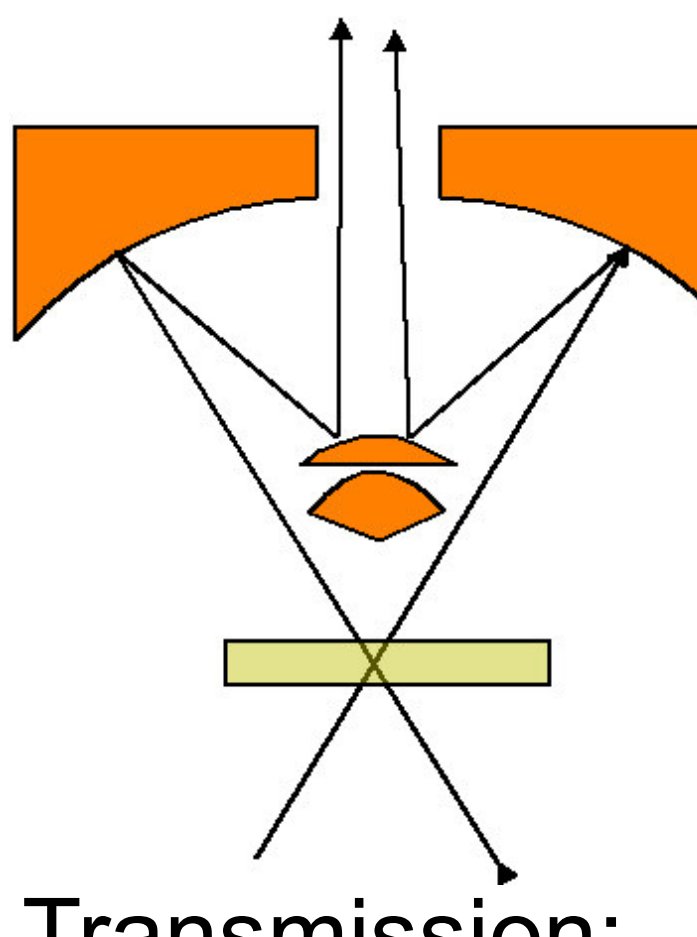
bulk information, transparent samples, e.g. membranes
HgCdTe (MCT) detector: res. $\sim 30 \mu \mathrm{m}$ $+X Y$ stage -> large scale mapping Imaging focal plane array (FPA) detector: res. $\sim 1 \mu \mathrm{m}$ $\rightarrow$ micro scale mapping

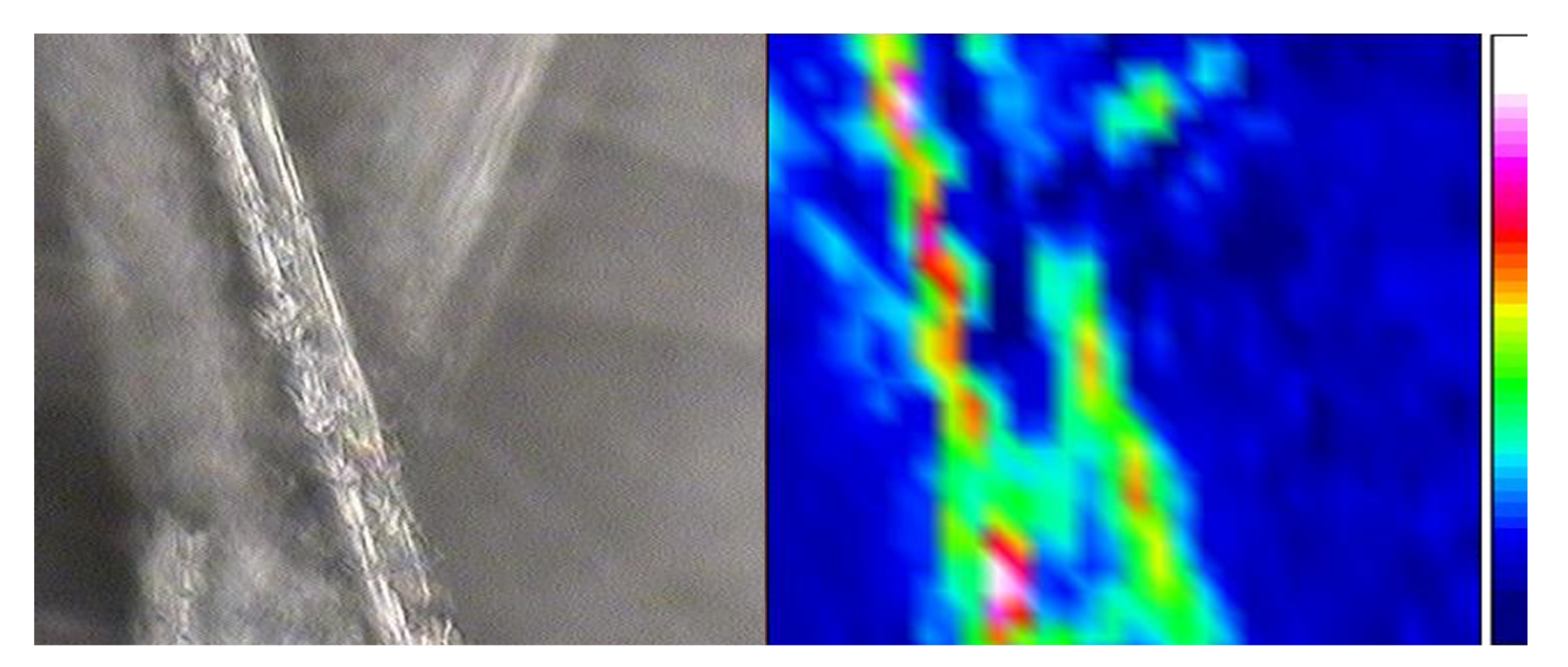

Optical and IR image of GDL focussed in carbon fibre:

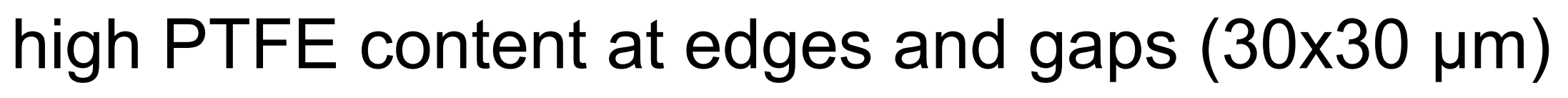

X-ray Photoemission Spectroscopy Detection of emitted core level electrons Elemental / chemical information

Surface sensitivity $<10 \mathrm{~nm}$
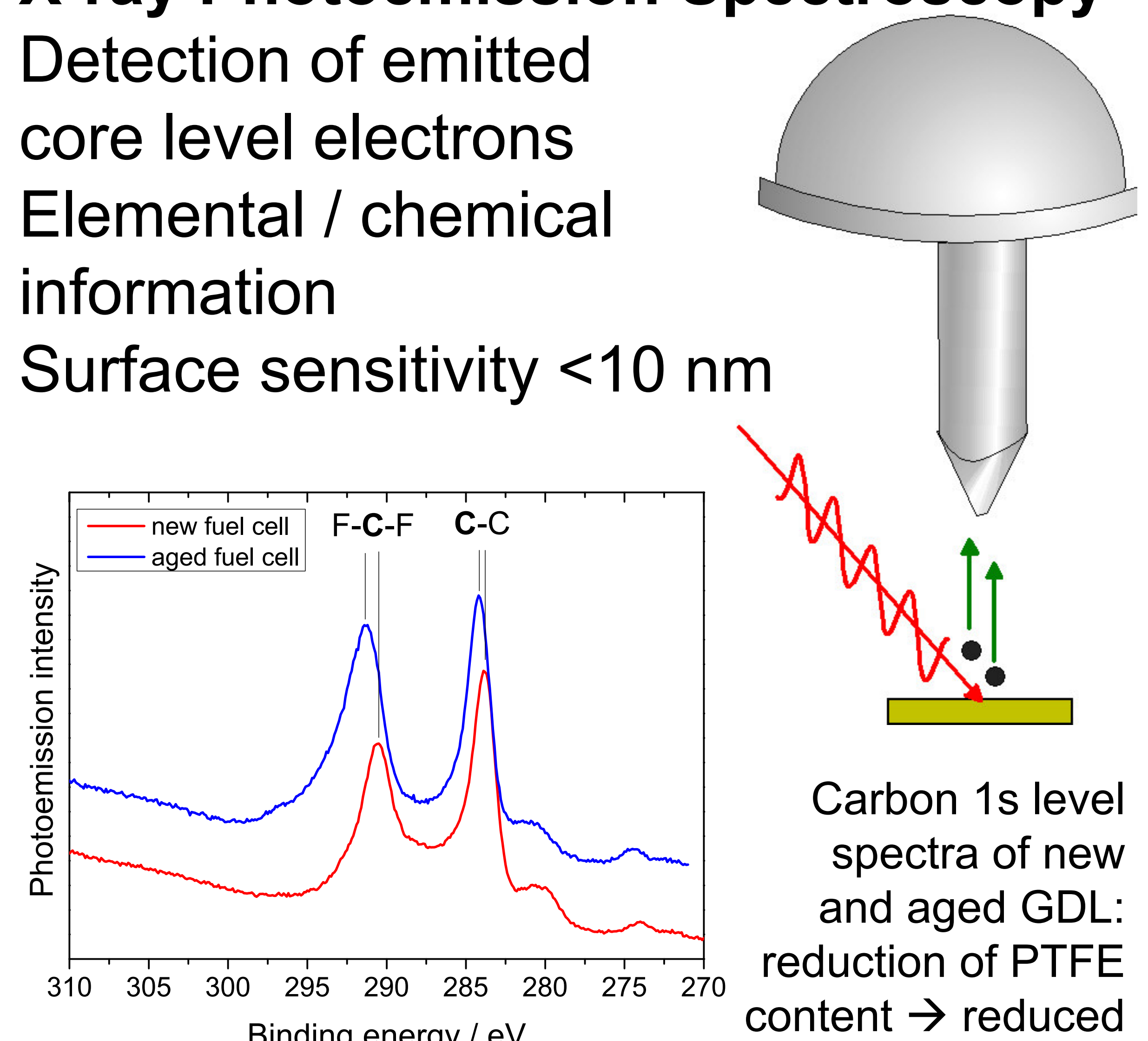

spectra of new and aged GDL: reduction of PTFE content $\rightarrow$ reduced

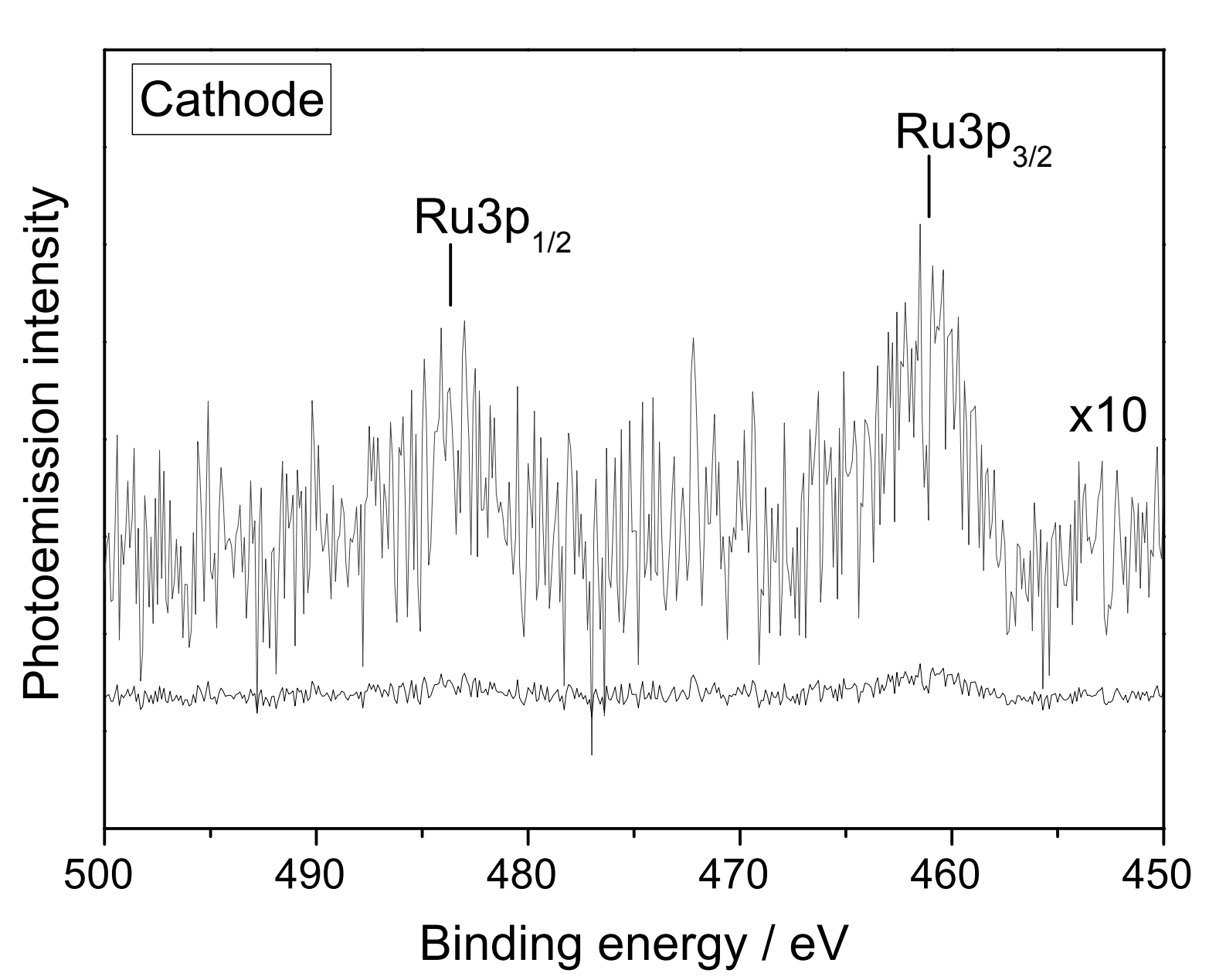

hydrophobicity

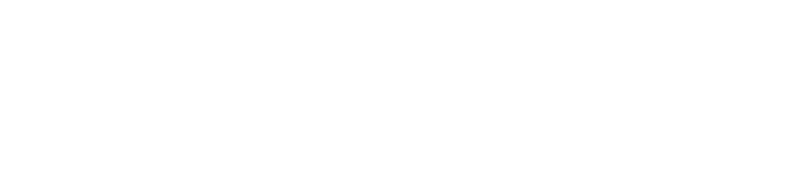

Spectrum of Ruthenium traces $(<0.5 \%)$ in a used electrode
Raman Vibrational Spectroscopy

Molecular vibrations related to polarisability changes

Variable excitation lasers $\rightarrow$ resonance enhancements, avoidance of fluorescence
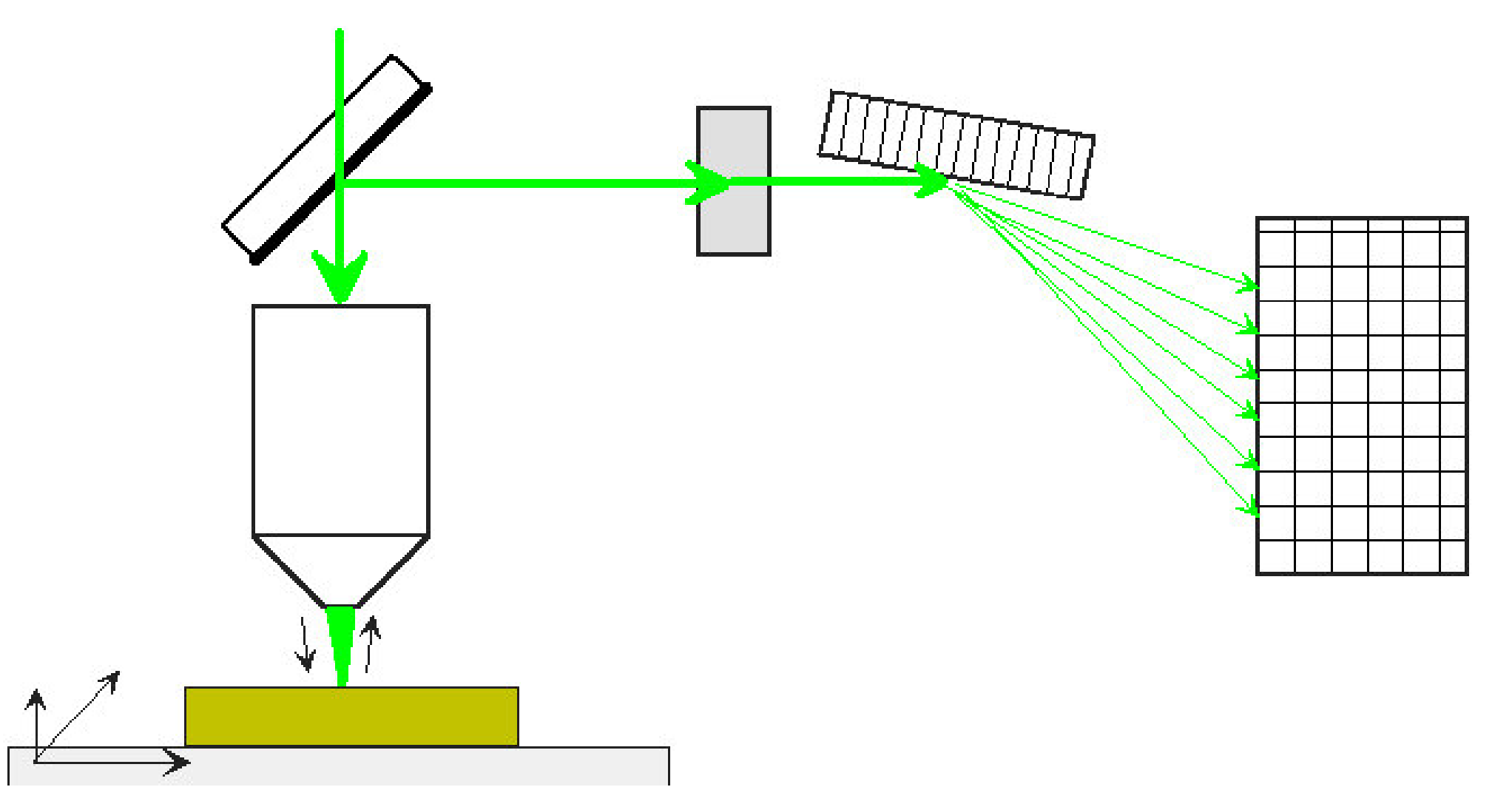

$X Y Z$ stage $\rightarrow$ mapping and $Z$ profiling

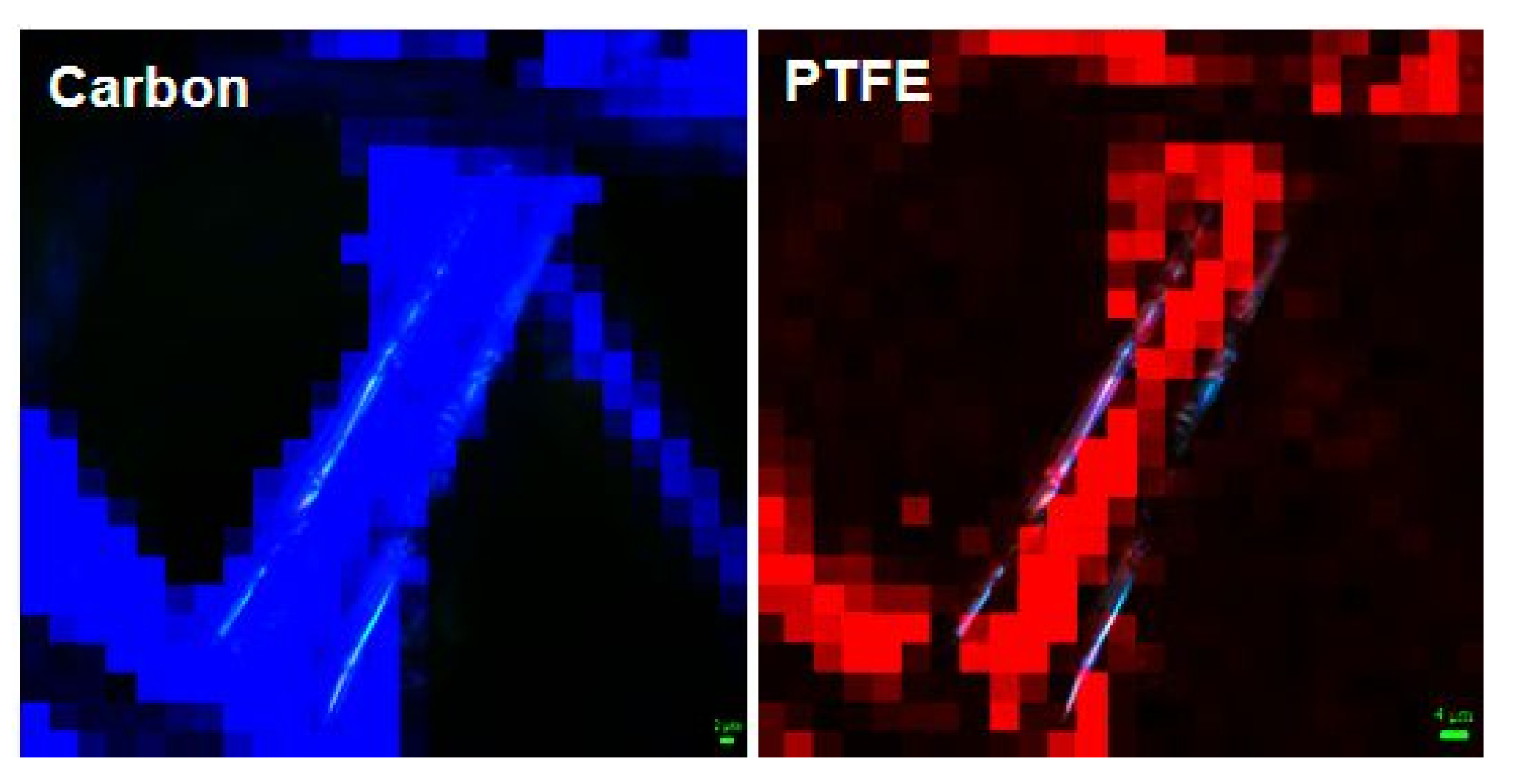

Image of GDL with Raman mapping overlay for $\mathrm{C}=\mathrm{C}$ vibrations and $\mathrm{C}-\mathrm{F}$ vibrations: distinction of carbon

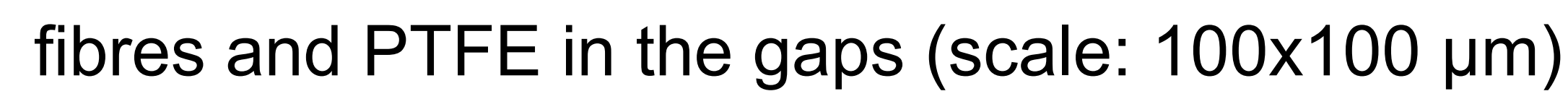

\section{Depth Profiling of Porous Materials}

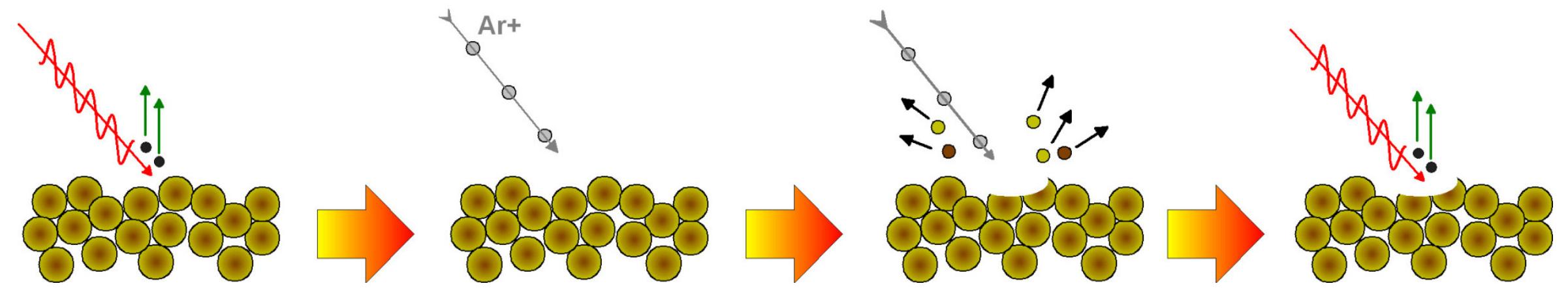

Ion etching $\rightarrow$ Bulk properties

vacuum conditions necessary

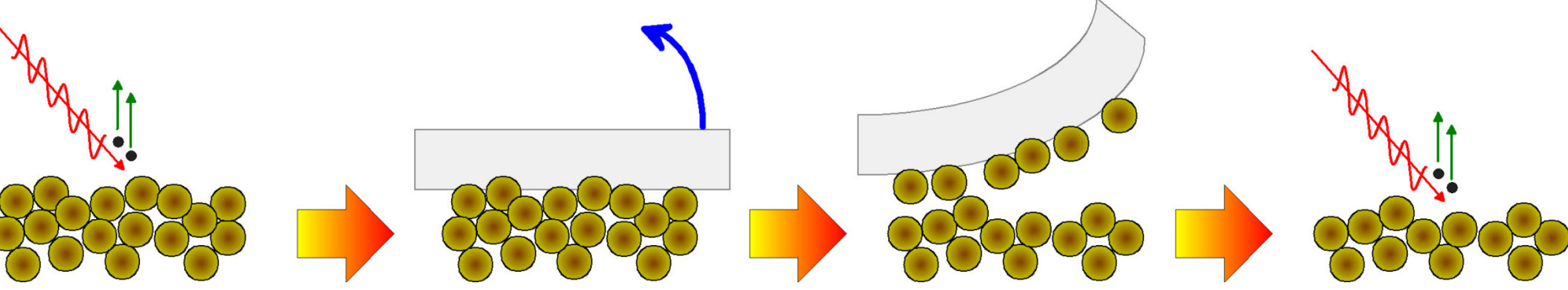

Adhesive tape delamination

$\rightarrow$ Inner surfaces of porous materials ambient conditions $\rightarrow$ combination with FTIR, Raman, XPS

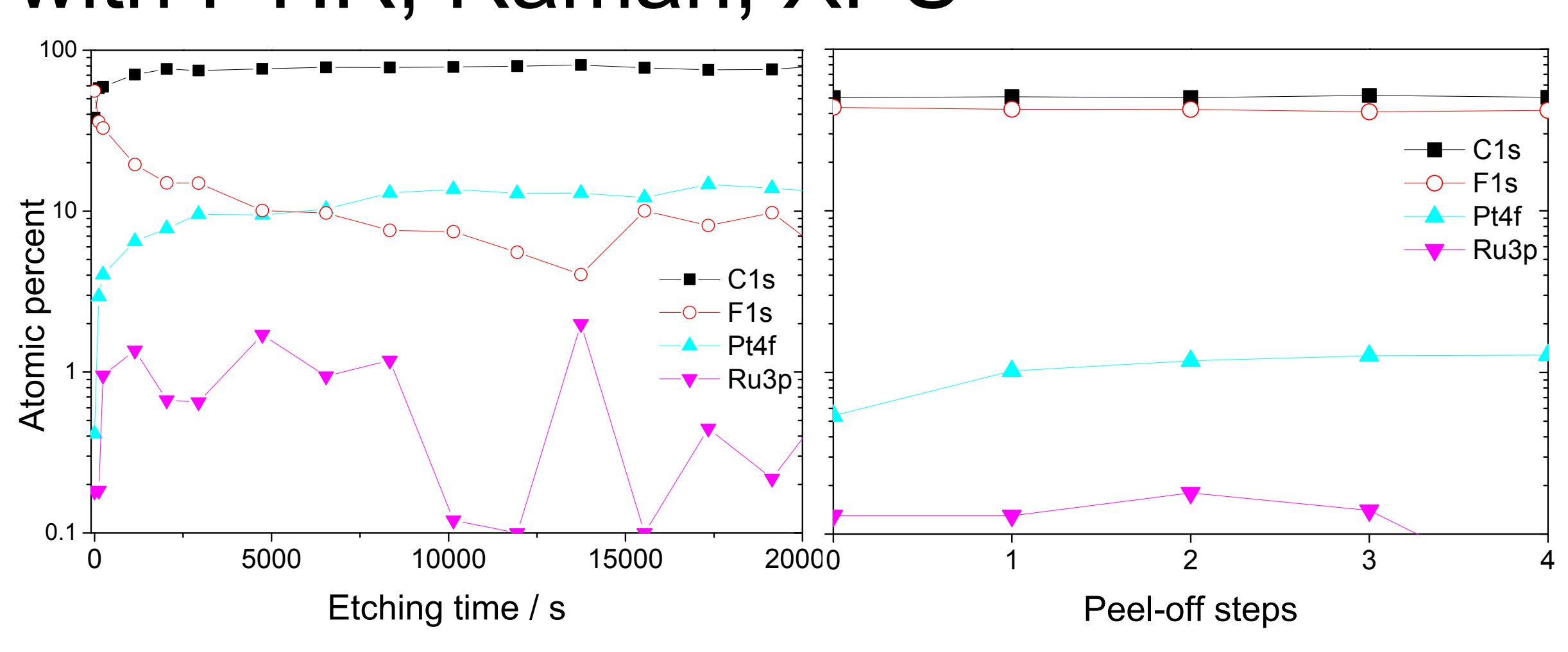

Ion etching (left) and delamination (right) XPS depth profile of an electrode:

-Stable fluorine signal at

inner surfaces

-Increasing $\mathrm{Pt}$

content 